\title{
Activation of Microglia by Histamine and Substance P
}

\author{
Jin Zhua, bhen Quc Xiang Luc Shu Zhang \\ ${ }^{a}$ Clinical Research Center, the First Affiliated Hospital of Nanjing Medical University, ${ }^{b}$ Department of \\ emergency, Nanjing First Hospital Affiliated to Nanjing Medical University, 'Department of Geriatrics, \\ the Second Affiliated Hospital of Nanjing Medical University, Nanjing, Jiangsu, P. R. China
}

\section{Key Words}

Microglial activation $\cdot$ Histamine $\cdot$ Substance $\mathrm{P} \cdot \mathrm{CNS}$ immune inflammation

\begin{abstract}
Background: Activated microglia perform many of the immune effector functions typically associated with macrophages. However, the regulators involved in microglial activation are not well defined. Because microglia play a pivotal role in immune surveillance of the CNS, we studied the effect of the neuromediators histamine and substance P on microglia. Methods: The induction of microglial activation by histamine and substance $P$ was examined using primary cultured microglia. Fluorescent images were acquired with a confocal microscope. The levels of TNF- $\alpha$ and IL- 6 were measured with a commercial ELISA kit. Intracellular reactive oxygen species (ROS) levels were determined by dichlorodihydrofluorescein oxidation. The mitochondrial membrane potential was assessed with the MitoProbe ${ }^{\mathrm{TM}} \mathrm{JC}-1$ assay kit. Results: We found that the neuromediators histamine and substance P were able to stimulate microglial activation and the subsequent production of ROS and proinflammatory factors TNF- $\alpha$ and IL-6. These effects were partially abolished by antagonists of the histamine receptors $\mathrm{H} 1$ and $\mathrm{H} 4$ and of the substance $\mathrm{P}$ receptors NK-1, NK-2 and NK-3. Histamine induced mitochondrial membrane depolarization in microglia. Conclusions: These results indicate that the neuromediators histamine and SP can trigger microglial activation and release of pro-inflammatory factors from microglia, thus contributing to the development of microgliamediated inflammation in the brain.
\end{abstract}

J. Zhu and C. Qu contributed equally to this work.

Prof. Shu Zhang,

and Prof. Xiang Lu
Clinical Research Center, The First Affiliated Hospital of Nanjing Medical University, Nanjing, Jiangsu, 210029 (P. R. China) and Department of Geriatrics, the Second Affiliated Hospital of Nanjing Medical University, Nanjing, Jiangsu 210029 (P. R. China)

E-Mail zszqs@hotmail.com and E-Mail luxiang66@njmu.edu.cn 
Zhu et al.: Microglia Activation by Histamine and SP

\section{Introduction}

Microglia, the resident immune cells in the brain, play a pivotal role in immune surveillance of the central nervous system (CNS). Consequently, these cells are likely to play an important role in determining either the development of protective immune responses or the progression of damaging inflammation during CNS diseases [1-4]. Microglia respond to traumatic injury and the presence of infectious organisms by migrating to the site of injury, where they proliferate. When subjected to abnormal stimulation, such as neurotoxins, neuronal debris, or injury, microglia become gradually activated and produce a host of factors, including tumor necrosis factor- $\alpha$ (TNF- $\alpha$ ), prostaglandin E2 (PGE2), interleukin-6 (IL-6), nitric oxide (NO), and reactive oxygen species (ROS). Accumulation of these proinflammatory and cytotoxic factors is directly deleterious to neurons and induces further activation of microglia, resulting in a vicious cycle $[5,6]$. Thus, the inhibition of microglial activation and subsequent inflammatory processes may identify novel therapeutic strategies for eliminating the deleterious effects of microglia [3]. However, the regulators and mechanisms involved in microglial activation are not fully known.

Histamine is a potent mediator of inflammation and a regulator of the innate and adaptive immune responses. Histamine induces local inflammation reactions either directly by acting on target cells or indirectly by activating other humoral and/or cellular effector systems. Histamine released from mast cells can promote Th1 and Th2 cell activation [7]. Four histamine receptors have been identified: $\mathrm{H}_{1}, \mathrm{H}_{2}, \mathrm{H}_{3}$ and $\mathrm{H}_{4}$ [8-11]. Substance P (SP) is widely distributed in the central and peripheral nervous systems of vertebrates [12]. SP enhances lymphocyte proliferation, immunoglobulin production, and cytokine secretion from lymphocytes, monocytes, macrophages, and mast cells. The SP-induced release of inflammatory mediators, such as cytokines, oxygen radicals, arachidonic acid derivatives, and histamine, potentiates tissue injury and stimulates further leukocyte recruitment, thereby amplifying the inflammatory response [13]. SP can also increase vascular permeability, thus facilitating the development of an inflammatory response [14]. SP is an important proinflammatory neuropeptide that functions as an immunoneuromodulator in the brain $[15,16]$. This was demonstrated by inhibiting the SP-SP receptor interactions in vivo, which diminished the inflammatory responses [17], and by using mice genetically devoid of SP-SP receptor interactions [18]. Central to the ability of SP to augment inflammation is its role in modulating the function of myeloid cells, such as macrophages and dendritic cells, via SP-specific neurokinin (NK) receptors $[19,20]$. SP is a ligand for the NK-1 receptor and also displays some affinity for the NK-2 receptor [21]. As such, substance P has the potential to interact with a number of CNS cell types that bear substance P receptors, including neurons, astrocytes and oligodendrocytes. It has also been reported that microglia expresses the SP gene and NK-1 receptor [22]. However, little is known about the role of the neuromediators histamine and SP in brain microglia activation.

We have previously reported that the mast cell tryptase induces microglial activation and release of inflammatory factors [23]. In this study, we investigate whether the neuromediators histamine and SP can affect microglial activation and the subsequent production of proinflammatory factors.

\section{Materials and Methods}

\section{Reagents}

Dulbecco's modified Eagle's medium (DMEM) and fetal calf serum (FCS) were purchased from GibcoBRL (Grand Island, NY, USA). Histamine, SP, and 3-(4, 5-dimethylthiazol-2-yl)-2-,5-diphenyltetrazolium bromide (MTT) were purchased from Sigma-Aldrich (St. Louis, MO, USA). The $\mathrm{H}_{1} \mathrm{R}$ antagonist cetirizine dihydrochloride (cetirizine), $\mathrm{H}_{2} \mathrm{R}$ antagonist ranitidine hydrochloride (ranitidine), $\mathrm{H}_{3} \mathrm{R}$ antagonist carcinine ditrifluoroacetate (carcinine), $\mathrm{H}_{4} \mathrm{R}$ antagonist A943931 dihydrochloride (A943931), RP 67580 (a potent and selective tachykinin $\mathrm{NK}_{1}$ receptor antagonist), GR 159897 (a potent and selective non-peptide neurokinin 
Zhu et al.: Microglia Activation by Histamine and SP

$\mathrm{NK}_{2}$ receptor antagonist) and SB 218795 (a potent, selective and competitive non-peptide $\mathrm{NK}_{3}$ receptor antagonist) were purchased from Tocris Bioscience (Bristol, UK). The mouse anti-rat ED8 (anti-CD11b/ CD18) monoclonal antibody (a marker for complement receptor 3 of activated microglia) was purchased from AbD Serotec (Raleigh, NC, USA). Fluoroshield mounting medium with 4,6-diamidino-2-phenylindole (DAPI) was purchased from Abcam (HK, China). The Rat IL-6 Immunoassay Kit and Rat TNF- $\alpha$ Immunoassay Kit were obtained from R\&D Systems, Inc. (Minneapolis, MN, USA). The LIVE green reactive oxygen species detection kit and MitoProbe ${ }^{\mathrm{TM}}$ JC-1 assay kit were purchased from Molecular Probes, Invitrogen (Carlsbad, CA, USA).

\section{Microglia-enriched cultures}

Rat primary microglial cells were prepared according to a previously described protocol with slight modifications [24]. Briefly, tissues from whole brains of postnatal (P1-P2) Sprague-Dawley rats were triturated, and the cells were then plated on poly-D-lysine precoated cell culture flasks in DMEM containing $10 \%$ fetal calf serum, $100 \mathrm{U} / \mathrm{ml}$ penicillin, and $100 \mathrm{mg} / \mathrm{ml}$ streptomycin. The cultures were maintained at $37^{\circ} \mathrm{C}$ in a humidified atmosphere of $5 \% \mathrm{CO}_{2} / 95 \%$ air. After reaching a confluent monolayer of glial cells (10-14 days), microglia were separated from astrocytes by shaking off for $5 \mathrm{~h}$ at 100 r.p.m. and replated on 24-well culture plates at a density of $10^{5}$ cells $/ \mathrm{cm}^{2}$. After plating the microglia-enriched population for 24 $\mathrm{h}$, the cells were treated with lipopolysaccharide (LPS), histamine or substance P (SP) alone. The enriched microglia culture was $>98 \%$ pure, as determined by OX-42-IR.

\section{Cell viability assay}

Cell viability was measured by the Thiazolyl blue (MTT) method. Briefly, cells were collected and seeded in 96-well plates at a density of $10^{5}$ cells $/ \mathrm{cm}^{2}$. After incubation for $48 \mathrm{~h}$, the cells were exposed to fresh medium containing LPS $(0.01 \mu \mathrm{g} / \mathrm{ml})$ or various concentrations $(0.001,0.01,0.1 \mathrm{and} 1 \mu \mathrm{g} / \mathrm{ml})$ of histamine or SP at $37^{\circ} \mathrm{C}$. LPS was used as a positive control for microglial activation. After incubation for up to $24 \mathrm{~h}, 20 \mu \mathrm{L}$ MTT tetrazolium salt (dissolved in Hank's balanced salt solution at a final concentration of 5 $\mathrm{mg} / \mathrm{mL}$ ) was added to each well, and the cells were placed in $\mathrm{CO}_{2}$ incubator for $4 \mathrm{~h}$. Finally, the medium was aspirated from each well, and $150 \mu \mathrm{L}$ of DMSO was added to dissolve the formazan crystals. The absorbance of each well was measured using a Dynatech MR5000 plate counter at test and reference wavelengths of 570 and $630 \mathrm{~nm}$, respectively.

\section{Immunofluorescence}

To determine the effect of histamine and SP on microglial activation, cells were fixed with $4 \%$ paraformaldehyde for $30 \mathrm{~min}$. Nonspecific binding was then blocked by incubating the cells in a solution of $5 \%$ BSA and $0.1 \%$ Triton X-100 for $1 \mathrm{~h}$ at room temperature. The microglia were incubated with the ED8 monoclonal antibody (1:300), which recognizes complement receptor 3 (CD11b/CD18), overnight at $4^{\circ} \mathrm{C}$. After three washes with PBS, the microglia were incubated with a PE-conjugated secondary antibody (1:200), and nuclei were stained with DAPI. After three washes in PBS, the cells were smeared on glass slides, and coverslips were placed and sealed with nail polish. Fluorescent images were acquired by using a confocal microscope.

\section{TNF- $\alpha$ and IL-6 assays}

The amounts of TNF- $\alpha$ and IL- 6 in the culture medium were measured with commercial ELISA kits from R\&D Systems.

\section{Intracellular reactive oxygen species assay}

The production of intracellular reactive oxygen species (ROS) was measured by DCFH oxidation. The DCFH-DA reagent passively enters cells, where it is de-acetylated by an esterase to produce the nonfluorescent DCFH. Inside the cell, DCFH reacts with ROS to form DCF, the fluorescent product. For this assay, $10 \mathrm{mM}$ DCFH-DA was dissolved in methanol and diluted 500-fold in HBSS, to give a $20 \mu \mathrm{M}$ concentration of DCFHDA. Enriched-microglia cultures, seeded $\left(5 \times 10^{4}\right)$ in 96-well plates, were then exposed to DCFH-DA for $1 \mathrm{~h}$, followed by a 2-h treatment with HBSS containing several concentrations of LPS, histamine or substance P. After incubation, the fluorescent signal from dichlorofluorescein (DCF; excitation $495 \mathrm{~nm}$, emission 529 $\mathrm{nm}$ ) was registered every $2 \mathrm{~min}$, for up to $20 \mathrm{~min}$ of incubation, in a Perkin-Elmer LS-5B Luminescence 
Spectrometer (Perkin-Elmer, Oak Brook, IL, USA) $[25,26]$. To calculate the amount of intracellular ROS produced, the mean signal of the control group was subtracted from that of each treatment group. Four independent sets of samples were analyzed.

\section{Measurement of mitochondrial membrane potential in microglia}

The mitochondrial membrane potential $\left(\Delta \Psi_{m}\right)$ of microglia was assessed with the MitoProbe ${ }^{\mathrm{TM}}$ JC-1 Assay Kit (Molecular Probes, Invitrogen). JC-1 exhibits potential-dependent accumulation in mitochondria, resulting in a fluorescence emission shift from green $(\sim 529 \mathrm{~nm})$ to red $(\sim 590 \mathrm{~nm})$. Consequently, mitochondrial depolarization is indicated by a decrease in the red/green fluorescence intensity ratio. The potential-sensitive color shift is due to the concentration-dependent formation of red fluorescent J-aggregates. Microglia, suspended in $1 \mathrm{ml} \mathrm{PBS}$ at approximately $1 \times 10^{6} \mathrm{cells} / \mathrm{ml}$, were incubated with $2 \mu \mathrm{M}$ of JC- 1 for 15 minutes at $37^{\circ} \mathrm{C}$. The cells were washed and resuspended in $500 \mu \mathrm{l} \mathrm{PBS}$ and then analyzed on a flow cytometer with $488 \mathrm{~nm}$ excitation using emission filters appropriate for Alexa Fluor 488 dye and R-phycoerythrin. A decrease in the red/green fluorescence intensity ratio was interpreted as a loss of $\Delta \Psi_{\mathrm{m}^{\prime}}$ whereas an increase in the ratio was interpreted as a gain in $\Delta \Psi_{\mathrm{m}}$.

\section{Statistical Analysis}

All values shown are means \pm SEM. The significance of the difference between the control samples and samples treated with various drugs was determined by one-way ANOVA followed by the post-hoc least significant difference test. Differences were considered significant at $\mathrm{P}<0.05$.

\section{Results}

Histamine and SP induced microglial activation

Cell survival, measured by 3-(4, 5-dimethylthiazol-2-yl) 2, 5-diphenyl tetrazolium bromide (MTT) analysis, revealed that a 24 -h incubation with LPS $(0.01 \mu \mathrm{g} / \mathrm{ml})$ or various concentrations $(0.001,0.01,0.1$ and $1 \mu \mathrm{g} / \mathrm{ml})$ of histamine or SP had no effect on microglia viability (date not shown).

Activated microglia were detected with the monoclonal antibody ED8, which recognizes complement receptor 3 (CR3). LPS $(0.01 \mu \mathrm{g} / \mathrm{ml})$ was used as a positive control for microglial activation. Upon incubation with LPS $(0.01 \mu \mathrm{g} / \mathrm{ml})$, histamine $(0.1 \mu \mathrm{g} / \mathrm{ml})$ or SP $(0.1 \mu \mathrm{g} /$ $\mathrm{ml}$ ) for 24 hours, the ED8-positive expression (in red) was remarkably upregulated (Fig. 1). These results suggest that the neuromediators histamine and SP could activate microglia.

\section{Histamine and SP induced TNF- $\alpha$ release from microglia}

As microglia-mediated neuroinflammation is mainly due to an excess of proinflammatory and cytotoxic factors from activated microglia and theses factors' downstream signaling cascades, the levels of proinflammatory factors were determined. As shown in Fig. 2, incubation with LPS $(0.01 \mu \mathrm{g} / \mathrm{ml})$ for $24 \mathrm{~h}$ significantly increased the production of TNF- $\alpha$ $(\mathrm{P}<0.01$ vs. control). Incubation with histamine at $0.001,0.01,0.1$ and $1 \mu \mathrm{g} / \mathrm{ml}$ for $24 \mathrm{~h}$ produced a concentration-dependent increase in TNF- $\alpha$ levels to $572 \%, 965 \%, 1637 \%$ and $3413 \%$ of the control, respectively. Similarly, SP enhanced TNF- $\alpha$ production in microglia to $765 \%, 1374 \%$ and $2155 \%$ of the control at concentrations of $0.01,0.1$ and $1 \mu \mathrm{g} / \mathrm{ml}$, respectively. Exposure to LPS $(0.01 \mu \mathrm{g} / \mathrm{ml})$ or histamine $(0.1 \mu \mathrm{g} / \mathrm{ml})$ for $30 \mathrm{~min}, 2 \mathrm{~h}, 6 \mathrm{~h}$ and $24 \mathrm{~h}$ enhanced the production of TNF- $\alpha$. SP $(0.1 \mu \mathrm{g} / \mathrm{ml})$ exerted similar effects on TNF- $\alpha$ production (Fig. 3). These results indicate that histamine and SP could induce TNF- $\alpha$ release from microglia.

\section{Histamine and SP induced IL-6 release from microglia}

Incubation with LPS $(0.01 \mu \mathrm{g} / \mathrm{ml})$ for $24 \mathrm{~h}$ significantly enhanced the microglial production of IL-6 to $727 \%$ of the control $(\mathrm{P}<0.01)$. The IL-6 level was also significantly elevated, to $466 \%$ and $548 \%$ of the control, after exposure to histamine at 0.1 and $1 \mu \mathrm{g} / \mathrm{ml}$, respectively. However, lower concentrations of histamine $(0.001$ and $0.01 \mu \mathrm{g} / \mathrm{ml})$ increased the IL-6 level but not in a statistically significant way compared with the control. SP also 
Fig. 1. Histamine and SP induced microglial activation. Primary microglia were treated with LPS $(0.01 \mu \mathrm{g} / \mathrm{ml})$, histamine $(0.1 \mu \mathrm{g} / \mathrm{ml})$ or SP $(0.1 \mu \mathrm{g} / \mathrm{ml})$ for 24 hours. LPS was used as a positive control for microglial activation. The cells were stained with the ED8 antibody and observed by confocal microscopy, revealing an upregulation of ED8-positive expression (red) in activated microglia. The blue staining represents DAPI. Scale bar: $50 \mu \mathrm{m}$.
Fig. 2. Effects of histamine $(0.001,0.01$, 0.1 and $1 \mu \mathrm{g} / \mathrm{ml}$ ) and SP (0.001, 0.01, 0.1 and $1 \mu \mathrm{g} / \mathrm{ml}$ ) on TNF- $\alpha$ release from microglia. LPS $(0.01 \mu \mathrm{g} / \mathrm{ml})$ was used as a positive control for microglial activation. ${ }^{* *} P<0.01$ vs. the control group. The data are presented as the mean \pm SEM of three independent experiments.
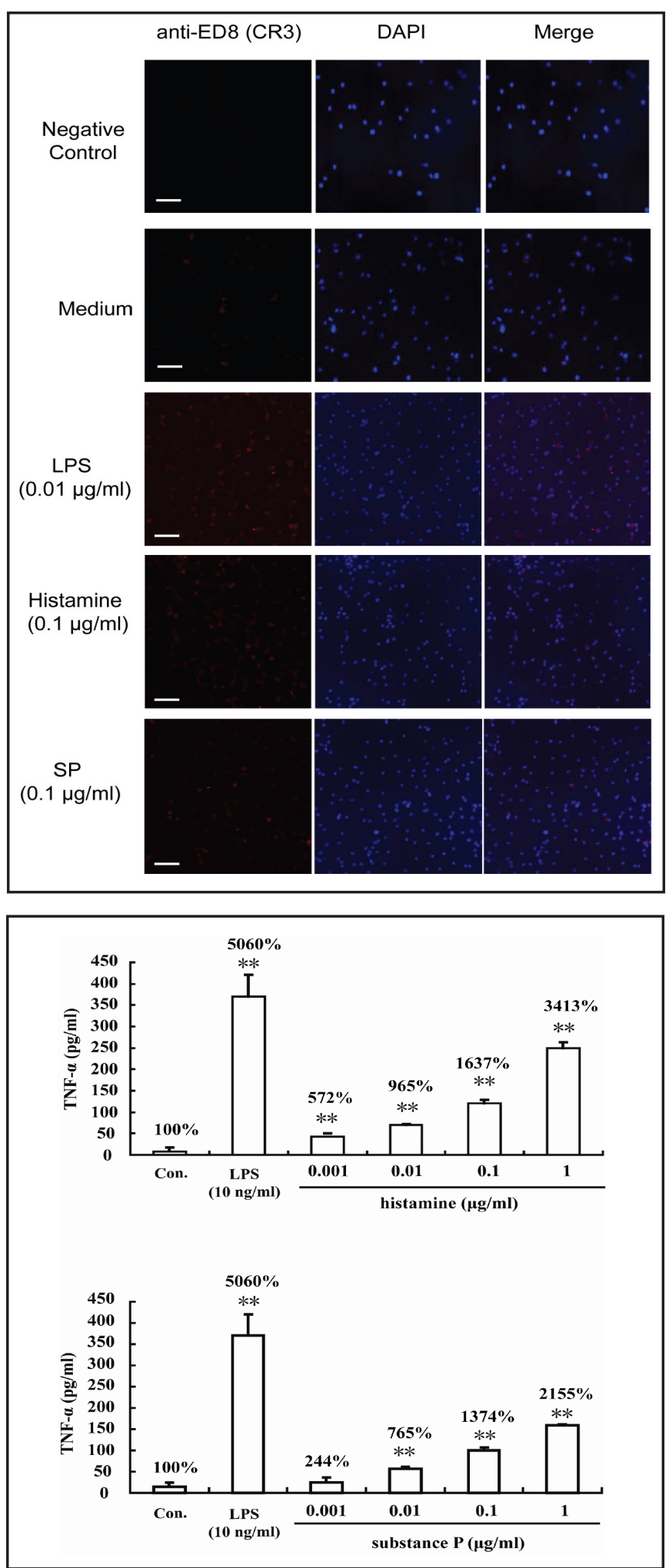

enhanced IL-6 production, with a minimum effective dose of $0.1 \mu \mathrm{g} / \mathrm{ml}$ (Fig. 4). Exposure to LPS $(0.01 \mu \mathrm{g} / \mathrm{ml})$ and histamine $(0.1 \mu \mathrm{g} / \mathrm{ml})$ for $30 \mathrm{~min}, 2 \mathrm{~h}, 6 \mathrm{~h}$ and $24 \mathrm{~h}$ increased the production of IL-6, and SP $(0.1 \mu \mathrm{g} / \mathrm{ml})$ had similar effects on IL-6 production (Fig. 5). These results indicate that histamine and SP could induce the production of IL-6 in microglia. 


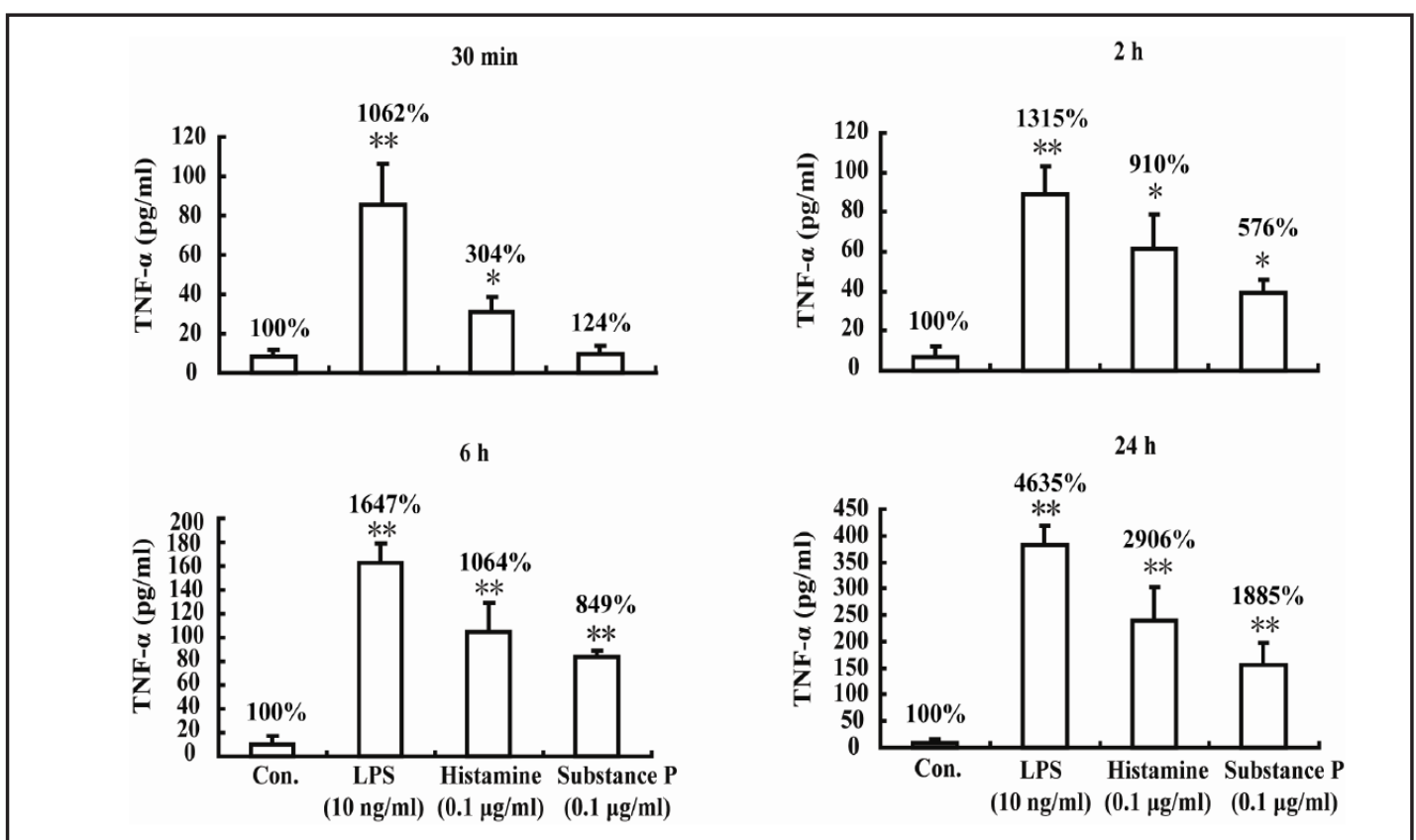

Fig. 3. Effects of exposure to histamine $(0.1 \mu \mathrm{g} / \mathrm{ml})$ and $\mathrm{SP}(0.1 \mu \mathrm{g} / \mathrm{ml})$ for $30 \mathrm{~min}, 2 \mathrm{~h}, 6 \mathrm{~h}$ and $24 \mathrm{~h}$ on TNF- $\alpha$ release from microglia. LPS $(0.01 \mu \mathrm{g} / \mathrm{ml})$ was used as a positive control for microglial activation. ${ }^{*} P<0.05$, ${ }^{* *} P<0.01 v$ s. the control group. The data are presented as the mean \pm SEM of three independent experiments.

Fig. 4. Effects of histamine $(0.001,0.01$, 0.1 and $1 \mu \mathrm{g} / \mathrm{ml})$ and SP $(0.001,0.01$, 0.1 and $1 \mu \mathrm{g} / \mathrm{ml}$ ) on IL-6 release from microglia. LPS $(0.01 \mu \mathrm{g} / \mathrm{ml})$ was used as a positive control for microglial activation. ${ }^{*} P<0.05,{ }^{* *} P<0.01$ vs. the control group. The data are presented as the mean \pm SEM of three independent experiments.

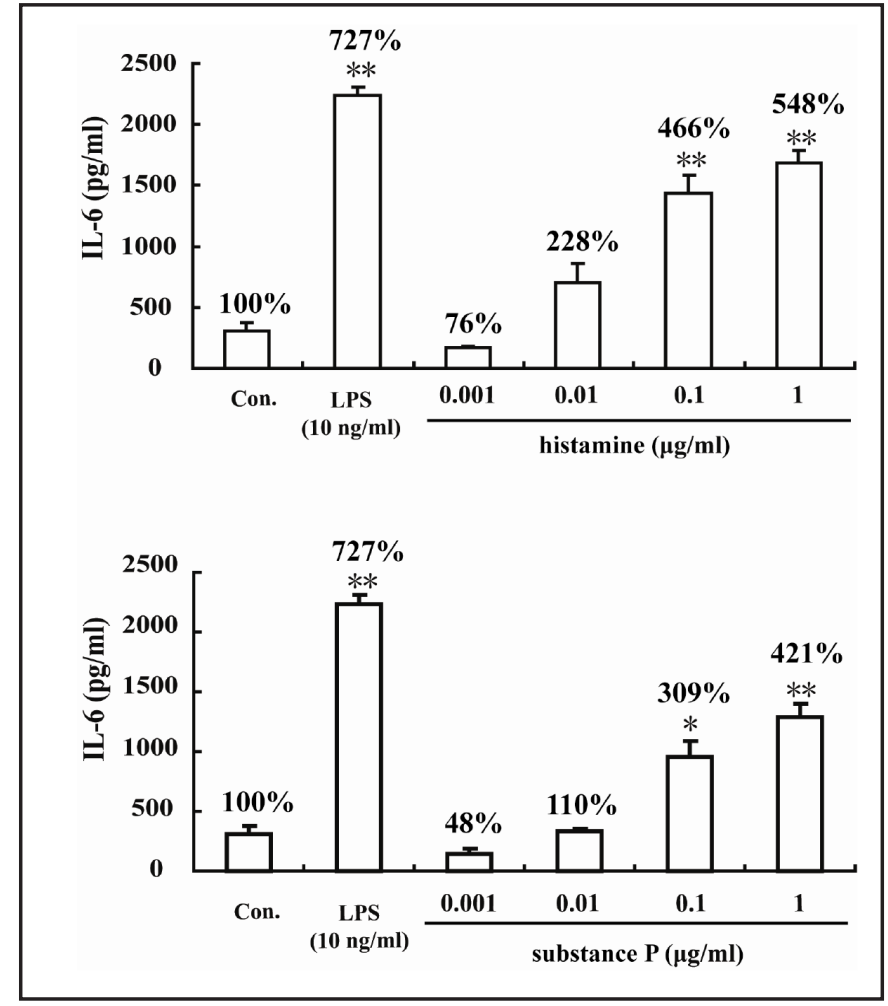

Histamine and SP induced ROS production in microglia

The production of ROS is another important indicator of microglial activation. Therefore, the effects of different treatments on the ROS levels were examined by fluorometry. As demonstrated in Fig. 6, the incubation with LPS $(0.01 \mu \mathrm{g} / \mathrm{ml})$ for $2 \mathrm{~h}$ induced the production 


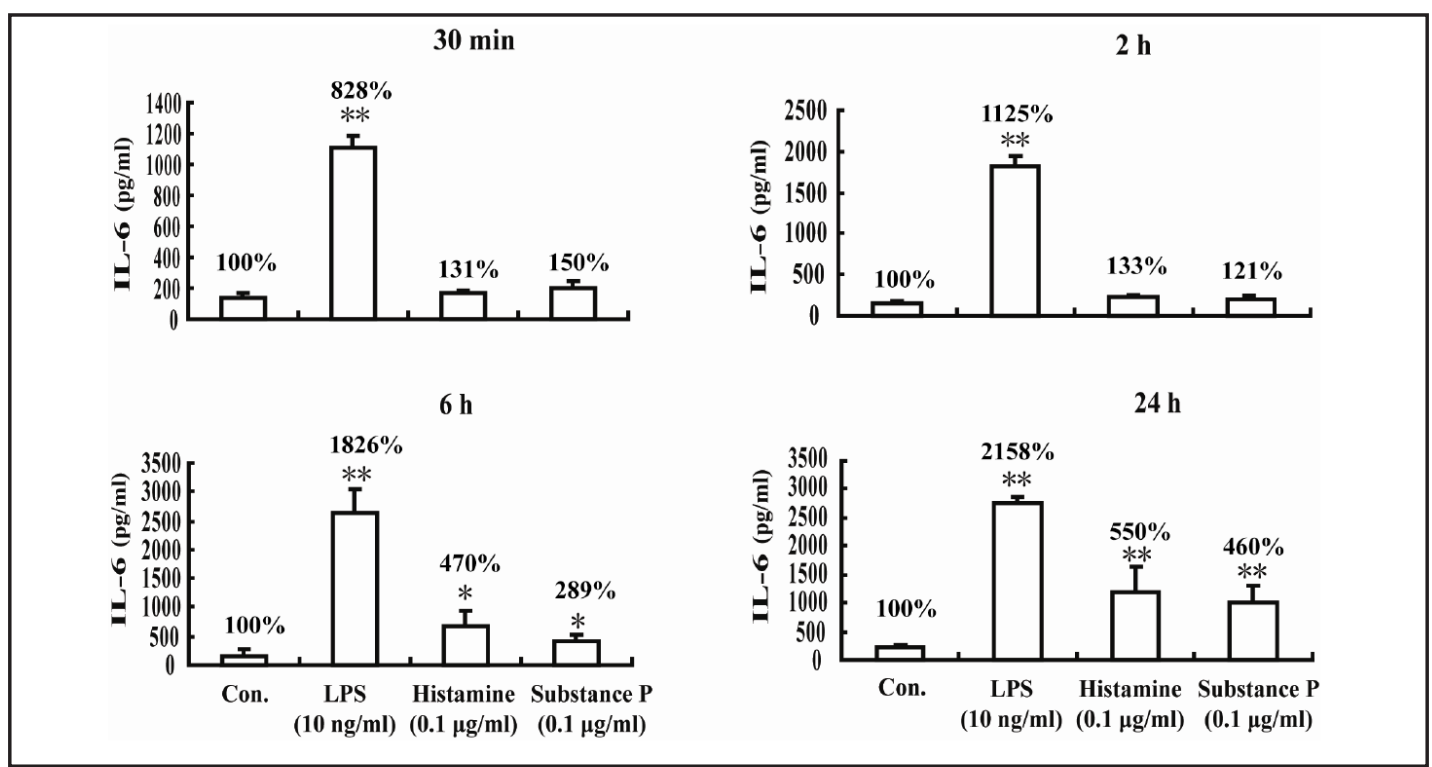

Fig. 5. Effects of exposure to histamine $(0.1 \mu \mathrm{g} / \mathrm{ml})$ and SP $(0.1 \mu \mathrm{g} / \mathrm{ml})$ for $30 \mathrm{~min}, 2 \mathrm{~h}, 6 \mathrm{~h}$ and $24 \mathrm{~h}$ on IL-6 release from microglia. LPS $(0.01 \mu \mathrm{g} / \mathrm{ml})$ was used as a positive control for microglial activation. ${ }^{*} P<0.05$, ${ }^{* *} P<0.01$ vs. the control group. The data are presented as the mean \pm SEM of three independent experiments.

Fig. 6. Effects of histamine $(0.001,0.01$, 0.1 and $1 \mu \mathrm{g} / \mathrm{ml})$ and SP $(0.001,0.01,0.1$ and $1 \mu \mathrm{g} / \mathrm{ml}$ ) on ROS production in microglia. The quantification of DCFH-DA fluorescence intensity is shown. LPS $(0.01 \mu \mathrm{g} /$ $\mathrm{ml}$ ) was used as a positive control for microglial activation. ${ }^{*} P<0.05,{ }^{* *} P<0.01 v s$. the control group. The data are presented as the mean \pm SEM of four independent experiments.

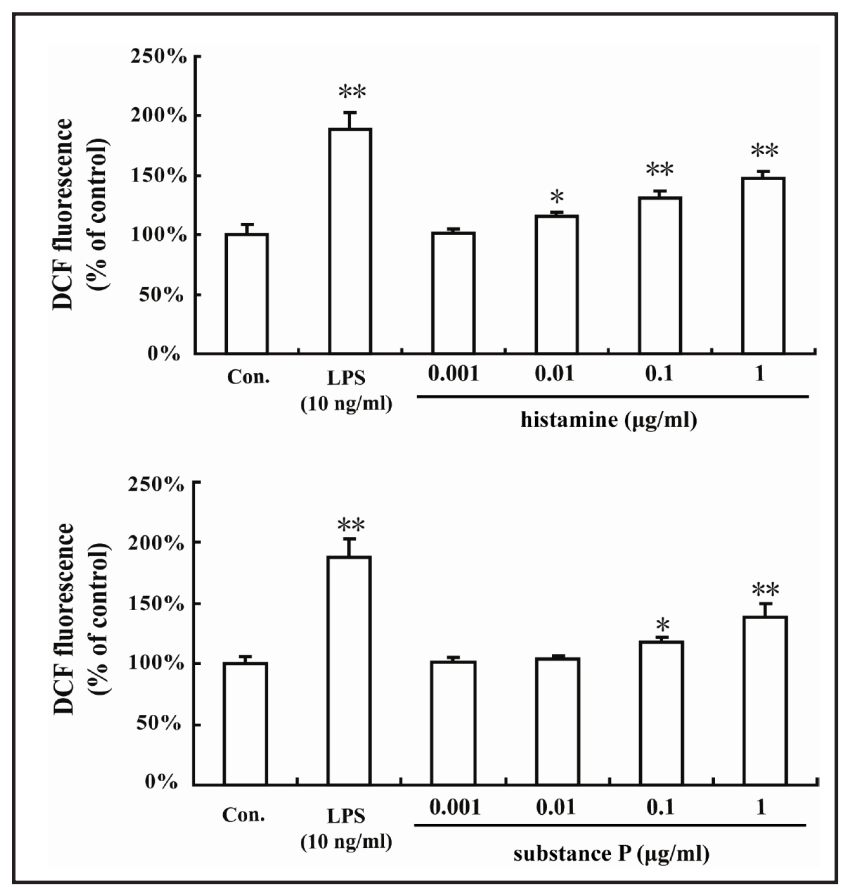

of ROS to $188 \%$ of the control level ( $\mathrm{P}<0.01$ vs. control). A 2-h incubation with histamine at $0.01,0.1$ and $1 \mu \mathrm{g} / \mathrm{ml}$ produced a concentration-dependent increase in the ROS level, to $115 \%, 131 \%$ and $148 \%$ of the control, respectively. Similarly, SP increased ROS production in microglia to $118 \%$ and $138 \%$ of the control at concentrations of 0.1 and $1 \mu \mathrm{g} / \mathrm{ml}$, respectively.

The effect of receptor antagonists on histamine- and SP-induced inflammatory factors and ROS release

We next examined the effects of antagonists of specific histamine receptors and the tachykinin receptor on inflammatory factors induced by histamine or SP and on ROS release from microglia. As shown in Fig. 7A, the $\mathrm{H}_{1} \mathrm{R}$ antagonist Cetirizine $(10 \mu \mathrm{M})$ and $\mathrm{H}_{4} \mathrm{R}$ 
A
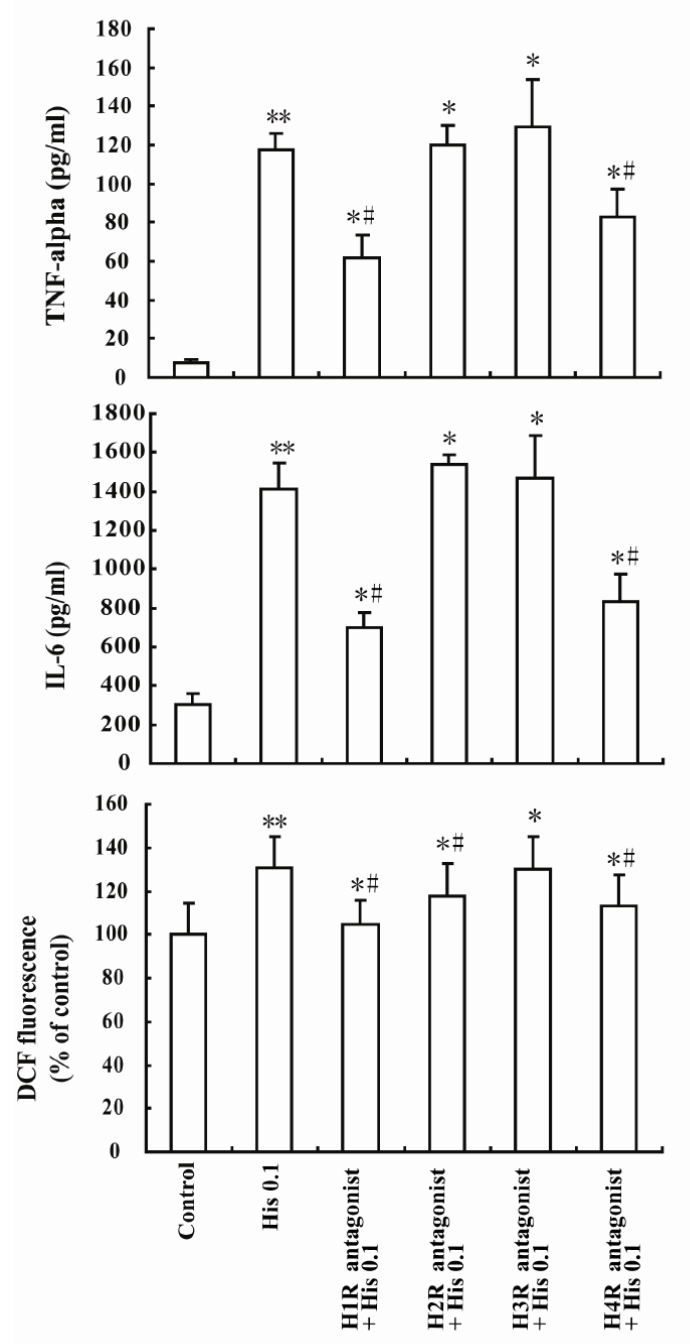

B
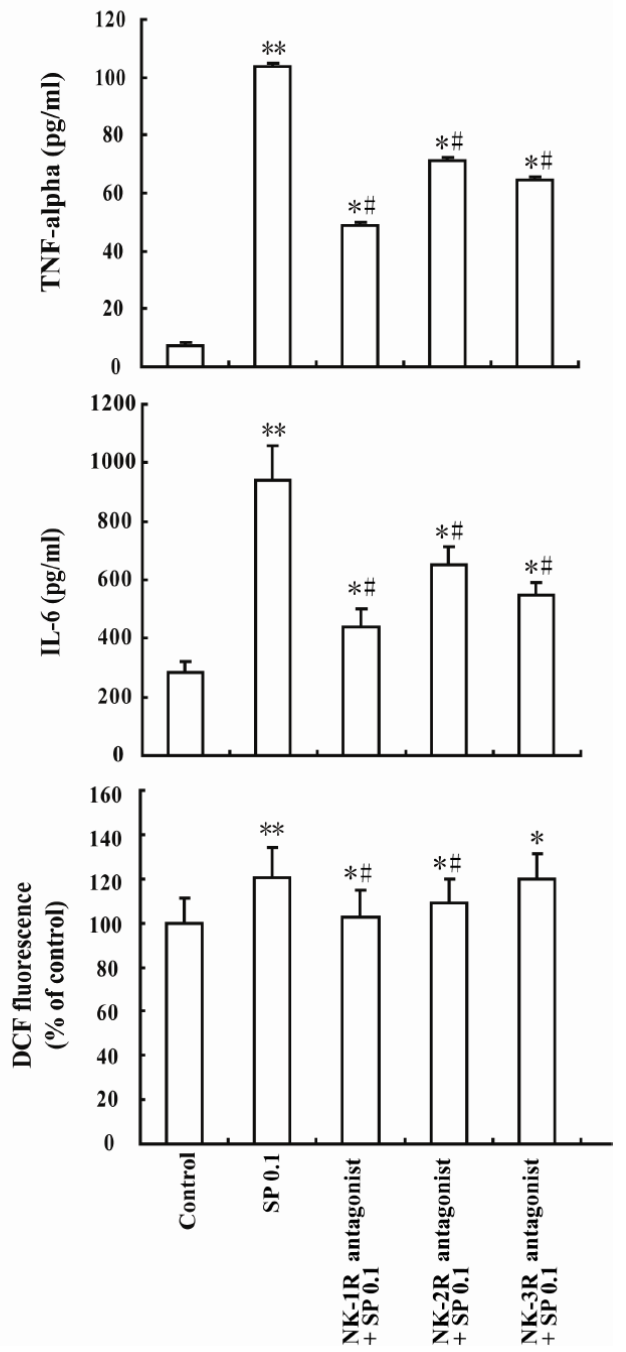

Fig. 7. Effects of receptor antagonists on histamine- and SP-induced inflammatory factors and ROS release. (A) The $\mathrm{H}_{1} \mathrm{R}$ antagonist Cetirizine $(10 \mu \mathrm{M}), \mathrm{H}_{2} \mathrm{R}$ antagonist Ranitidine $(10 \mu \mathrm{M}), \mathrm{H}_{3} \mathrm{R}$ antagonist Carcinine ditrifluoroacetate $(10 \mu \mathrm{M})$ and $\mathrm{H}_{4} \mathrm{R}$ antagonist $\mathrm{A} 943931(10 \mu \mathrm{M})$ were added to microglia 30 min before treatment with histamine $(0.1 \mu \mathrm{g} / \mathrm{ml})$ for $24 \mathrm{~h}$. (B) The NK-1R antagonist RP67580 (10 $\mu \mathrm{M})$, NK-2R antagonist GR159897 (3 $\mu \mathrm{M})$ and NK-3R antagonist SB $218795(3 \mu \mathrm{M})$ were added to microglia 30 min before treatment with SP $(0.1 \mu \mathrm{g} / \mathrm{ml})$ for $24 \mathrm{~h} .{ }^{*} P<0.05,{ }^{* *} P<0.01 v s$. the control group. ${ }^{\#} P<0.05$ vs. the histamine (His) or substance P (SP) $(0.1 \mu \mathrm{g} / \mathrm{ml})$ treatment groups. The data are presented as the mean \pm SEM of four independent experiments.

antagonist $\mathrm{A} 943931(10 \mu \mathrm{M})$ partially abolished the histamine $(0.1 \mu \mathrm{g} / \mathrm{ml})$-induced release of TNF- $\alpha$ and IL- 6 from microglia. In contrast, the $\mathrm{H}_{2} \mathrm{R}$ antagonist Ranitidine $(10 \mu \mathrm{M})$ and $\mathrm{H}_{3} \mathrm{R}$ antagonist Carcinine ditrifluoroacetate $(10 \mu \mathrm{M})$ had little effect on histamine-induced TNF- $\alpha$ and IL- 6 production. However, the antagonists of $\mathrm{H}_{1} \mathrm{R}, \mathrm{H}_{2} \mathrm{R}$ and $\mathrm{H}_{4} \mathrm{R}$ could partially abolish histamine-induced ROS production. In this study, we also found that the selective NK-1 receptor antagonist RP67580 $(10 \mu \mathrm{M})$, selective NK-2 receptor antagonist GR159897 $(3 \mu \mathrm{M})$ and NK-3 receptor antagonist SB $218795(3 \mu \mathrm{M})$ could partially abolished the SP $(0.1 \mu \mathrm{g} / \mathrm{ml})$-induced release of TNF- $\alpha$ and IL-6 from microglia. The NK-1 and NK-2 receptor antagonists could also partially abolish SP-induced ROS production (Fig. 7B). These results indicate that histamine was able to induce the release of inflammatory factors from microglia 
Fig. 8. Effects of histamine $(0.1 \mu \mathrm{g} / \mathrm{ml})$ and SP $(0.1 \mu \mathrm{g} / \mathrm{ml})$ on mitochondrial depolarization in microglia. The graph shows quantification of the mitochondrial membrane potential, expressed as the fluorescence intensity ratio of J-aggregates to JC-1 monomers (red:green). LPS (0.01 $\mu \mathrm{g} / \mathrm{ml}$ ) was used as a positive control for microglial activation. ${ }^{* *} P<0.01$ vs. the control group. The data are presented as the mean \pm SEM of three independent experiments.

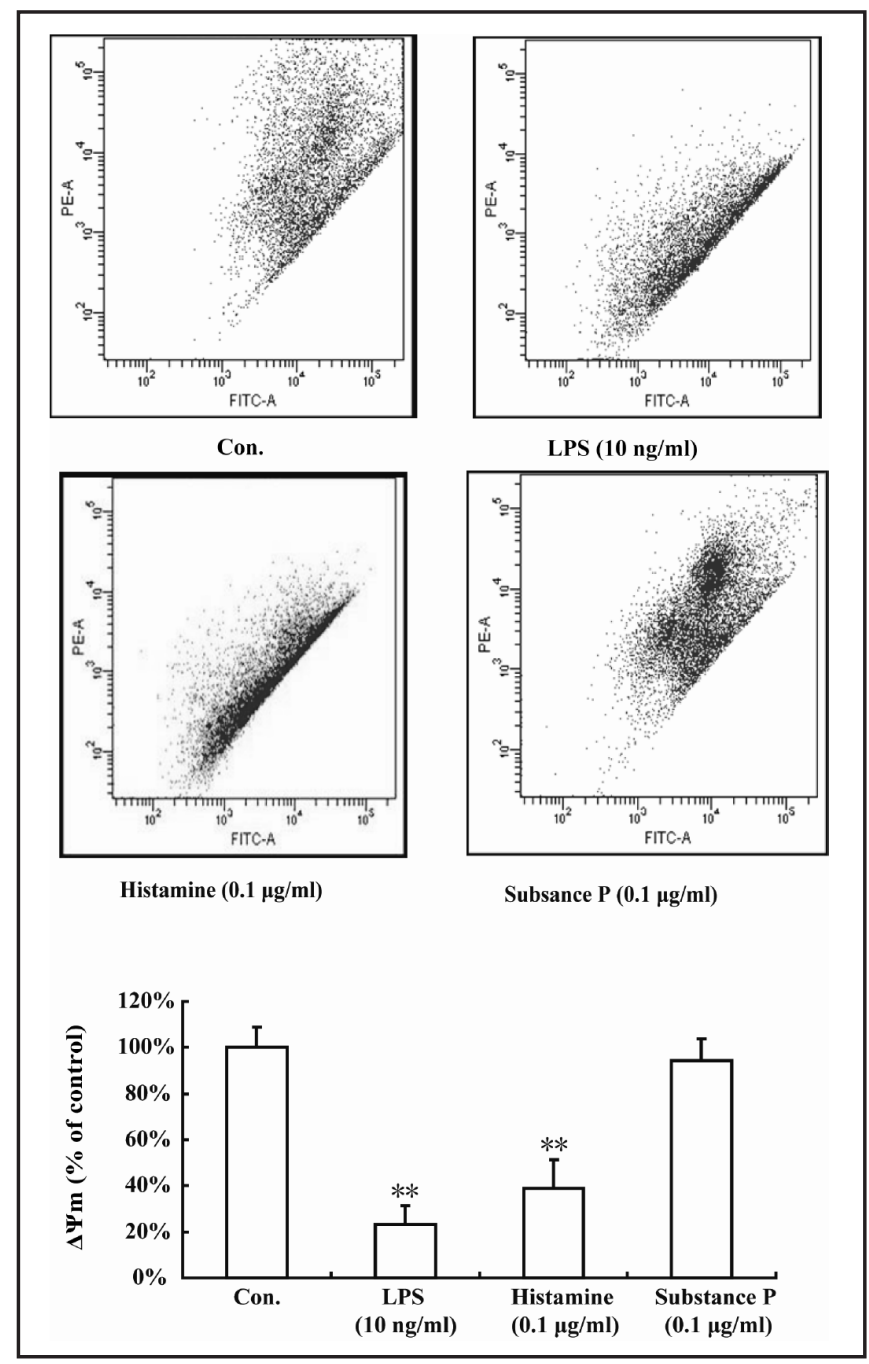

primarily via $\mathrm{H}_{1} \mathrm{R}$ and $\mathrm{H}_{4} \mathrm{R}$, whereas SP induced inflammatory factor release from microglia not only through the NK-1 receptor but also the NK-2 and NK-3 receptors.

Histamine induced the loss of mitochondrial membrane potential in microglia

As changes in the mitochondrial membrane potential $\left(\Delta \Psi_{\mathrm{m}}\right)$ have been shown to be involved in microglial activation and production of proinflammatory factors, the molecular probe JC-1 was used to detect the effect of histamine and SP on variations in the microglial mitochondrial membrane potential. As shown in Fig. 8, after exposure to LPS $(0.01 \mu \mathrm{g} / \mathrm{ml})$ for $30 \mathrm{~min}$, most microglia displayed a loss or collapse of $\Delta \Psi_{\mathrm{m}}$, indicated by a fluorescence shift of JC-1 from red-orange to greenish-yellow. Similarly, incubation with histamine $(0.1$ $\mu \mathrm{g} / \mathrm{ml})$ for $30 \mathrm{~min}$ reduced the $\Delta \Psi_{\mathrm{m}}$ of microglia. However, exposure to SP $(0.1 \mu \mathrm{g} / \mathrm{ml})$ for 30 min to $24 \mathrm{~h}$ caused no change in the $\Delta \Psi_{\mathrm{m}}$ of microglia These data indicate that histamine could induce mitochondrial membrane depolarization in microglia, whereas SP had no effect on the microglial $\Delta \Psi_{\mathrm{m}}$.

\section{Discussion}

Microglial activation has been shown to be an early sign that often precedes and triggers neuronal death in chronic neurodegenerative diseases $[3,5,27]$. A key proinflammatory protein synthesized and released by activated microglia is TNF- $\alpha$ [28]. The presence of 
elevated levels of TNF- $\alpha$ has been documented in many forms of neurodegenerative disease of both chronic (e.g., AD, Parkinson's disease, and amyotrophic lateral sclerosis) and acute (e.g., stroke and head trauma) types [29]. A recent study highlighted the crucial role of IL-6, one of the proinflammatory proteins released by activated microglia, within the CNS [30]. In the CNS, IL-6 can trigger inflammation-related cellular responses, including neurogenesis, gliogenesis, cell growth, cell survival, myelination and demyelination [31-33]. IL-6 is normally expressed at relatively low levels in the brain, but it is elevated in the cerebral spinal fluid and brain homogenates in the presence of brain injury or inflammation [34]. Therefore, the inhibition of microglial activation and subsequent neuroinflammation may offer a therapeutic benefit for neuroinflammation-related neurodegenerative disorders. The factors responsible for the overactivation of microglia are largely undefined. Here, we demonstrate that the neuromediators histamine and SP can induce microglial activation and release of inflammatory factors.

A significant amount of brain histamine is contained not only in neurons but also in brain mast cells $[35,36]$. The results presented in this study demonstrate that the interaction between microglia and histamine may modulate the activation of microglia and the production of IL-6, TNF- $\alpha$ and ROS in the activated microglia. However, the current understanding of histamine's effect on TNF- $\alpha$ and IL- 6 release from microglia is limited. We found that as little as $10 \mathrm{ng} / \mathrm{ml}$ of histamine was able to induce approximate increases of 5.7-fold in TNF- $\alpha$ release and 3.6-fold in IL-6 release from microglia, indicating that histamine is a potent stimulus of microglial activation. However, histamine did not induce the release of TNF- $\alpha$ in the N9 microglia cell line [37], possibly because the microglia cell line is less sensitive than primary cultured microglia. In addition, the N9 microglia cell line is mouse-derived, and there are differences in microglial activation between rat-derived and mouse-derived cells [38]. In the present study, we also found that histamine was able to induce enhanced ROS production. ROS are important molecules secreted by microglia [39]. A considerable amount of evidence suggests that oxidative stress induced by microglia-derived ROS is a major contributor to neurodegeneration [40,41]; this process involves activation of the p38 and JNK MAPKs through the upstream MKK signaling. The mitochondrial membrane potential and the downstream MAPKs have been shown to regulate microglial activation and the production of proinflammatory factors from microglia [42-45]. In the present study, we demonstrated that histamine induces mitochondrial membrane depolarization in microglia. These results suggest that histamine can induce microglial activation by reducing the mitochondrial membrane potential and regulating the downstream MAPKs.

It is now widely accepted that the neuropeptide SP can play an important role in augmenting inflammatory responses at peripheral sites. In particular, it has been demonstrated that SP can promote the immune functions of peripheral macrophages [46]. Binding of this neuropeptide to SP receptors (NK-1R) augments the production of proinflammatory monokines such as IL-1, IL-6, and TNF- $\alpha[47,48]$. Furthermore, SP can induce a respiratory burst in macrophages, resulting in the production of reactive oxygen intermediates [49]. However, much less is known about the role of this neuropeptide in the initiation and/or maintenance of inflammatory responses at the site of its most ubiquitous distribution, the CNS. Luber-Narod reported that substance P enhances the secretion of tumor necrosis factor-alpha from neuroglial cells stimulated with lipopolysaccharide [50]. In the present study, we found that SP could induce the release of TNF- $\alpha$ and IL- 6 from microglia. However, SP had no effect on the microglial mitochondrial membrane potential. Lai examined the expression of substance $\mathrm{P}$ and its receptor in human fetal brain microglia [51]. The ability of substance P to modulate immune cell function depends on its interaction with its receptor neurokinin-1, which is expressed in a variety of immune cells, including microglia [52]. We also found that SP could increase ROS generation in microglia; we therefore propose that SP induces the production of proinflammatory factors in microglia through elevated levels of mitochondria-derived ROS and phosphorylation by downstream MAPKs. Substance P was suggested to activate NK-1, but this has yet to be demonstrated, and a contribution of the tachykinin receptors NK-2 and NK-3 cannot be ruled out. In this study, 
we found that antagonists of NK-1R, NK-2R or NK-3R could partially abolish the release of SPinduced proinflammatory factors. These results suggest that not only the $\mathrm{NK}_{1}$ receptor but the $\mathrm{NK}_{2}$ and $\mathrm{NK}_{3}$ receptors are also involved in SP-induced microglial activation. However, the induction of microglial ROS production by SP occurs primarily through the NK-1 and NK-2 receptors. Understanding the detailed mechanism of SP-induced microglial activation requires further study.

Our subsequent experiments showed that histamine appears to induce the release of TNF- $\alpha$ and IL- 6 from microglia via a similar mechanism, which depends at least partially on the activation of $\mathrm{H}_{1} \mathrm{R}$ and $\mathrm{H}_{4} \mathrm{R}$. It is generally thought that the stimulatory effects of histamine on the immune system are mediated by $\mathrm{H}_{1} \mathrm{R}$, whereas the inhibitory effects most frequently involve $\mathrm{H}_{2} \mathrm{R}$ [53]. This concept has also been supported by a model of multiple sclerosis (MS), which showed that the dual effects of histamine are due to different pathophysiological features of four histamine receptors. Thus, $\mathrm{H}_{1} \mathrm{R}$ and $\mathrm{H}_{4} \mathrm{R}$ may participate in exacerbating the disease, and $\mathrm{H}_{2} \mathrm{R}$ and $\mathrm{H}_{3} \mathrm{R}$ may be effective in ameliorating the disease [54]. These results indicate that histamine most likely exerts a proinflammatory effect on microglia via $\mathrm{H}_{1} \mathrm{R}$ and $\mathrm{H}_{4} \mathrm{R}$. However, we found that histamine induces ROS production mainly through $\mathrm{H}_{1} \mathrm{R}, \mathrm{H}_{2} \mathrm{R}$ and $\mathrm{H}_{4} \mathrm{R}$; thus, this might involve a different mechanism from that of proinflammatory factor release.

In summary, we have shown here that the neuromediators histamine and SP can induce microglial activation and the subsequent production of proinflammatory factors. These results suggest that histamine and SP might play an important role in microglial activation and neuroinflammation-related diseases and further our understanding of the regulators and mechanisms involved in the activation of microglia.

\section{Disclosure Statement}

The authors declare that there are no conflicts of interest regarding the publication of this paper.

\section{Acknowledgements}

This project was sponsored the National Natural Science Foundation of China (No. 81102422, 81373398); the Natural Science Foundation of Jiangsu Province (BK2010020); and a Project Funded by the Priority Academic Program Development of Jiangsu Higher Education Institutions (PAPD).

\section{References}

- Csuka E, Hans VH, Ammann E, Trentz 0, Kossmann T, Morganti-Kossmann MC: Cell activation and inflammatory response following traumatic axonal injury in the rat. Neuroreport 2000;11:2587-2590.

$\checkmark 2$ Popovich PG: Immunological regulation of neuronal degeneration and regeneration in the injured spinal cord. Prog Brain Res 2000;128:43-58.

3 Gao HM, Liu B, Zhang W, Hong JS: Novel anti-inflammatory therapy for Parkinson's disease. Trends Pharmacol Sci 2003;24:395-401.

4 Heppner FL, Greter M, Marino D, Falsig J, Raivich G, Hovelmeyer N, Waisman A, Rulicke T, Prinz M, Priller J, Becher B, Aguzzi A: Experimental autoimmune encephalomyelitis repressed by microglial paralysis. Nat Med 2005;11:146-152.

5 Block ML, Hong JS: Microglial and inflammation-mediated neurodegeneration: multiple triggers with a common mechanism. Prog Neurobiol 2005;76:77-98. 
6 Herrera AJ, Tomas-Camardiel M, Venero JL, Cano J, Machado A: Inflammatory process as a determinant factor for the degeneration of substantia nigra dopaminergic neurons. J Neural Transm 2005;112:111-119.

7 Jutel M, Watanabe T, Klunker S, Akdis M, Thomet OA, Malolepszy J, Zak-Nejmark T, Koga R, Kobayashi T, Blaser K, Akdis CA: Histamine regulates T-cell and antibody responses by differential expression of H1 and $\mathrm{H} 2$ receptors. Nature 2001;413:420-425.

8 Akdis CA and Simons FE: Histamine receptors are hot in immunopharmacology. Eur J Pharmacol 2006;533:69-76.

-9 Repka-Ramirez MS and Baraniuk JN: Histamine in health and disease. Clin Allergy Immunol 2002;17:1-25.

$\checkmark 10$ Tiligada E, Zampeli E, Sander K, Stark H: Histamine H3 and H4 receptors as novel drug targets. Expert Opinion on Investigating Drugs 2009;18:1519-1531.

11 Huang JF and Thurmond RL: The new biology of histamine receptors. Current Allergy and Asthma Reports 2008;8:21-27.

12 Maggi CA: Principles of tachykininergic co-transmission in the peripheral and enteric nervous system. Regul Pept 2000;93:53-64.

13 Holzer P, Holzer-Petsche U: Tachykinins in the gut. Part II. Roles in neural excitation, secretion, and inflammation. Pharmacol Ther 1997;73:219-263.

14 O'Connor TM, O'Connell J, O’Brien DI, Goode T, Bredin CP, Shanahan F: The role of substance P in inflammatory disease. J Cell Physiol 2004;201:167-180.

15 Donkin JJ, Turner RJ, Hassan I, Vink R: Substance P in traumatic brain injury. Prog Brain Res 2007;161:97109.

16 Ebner K, Singewald N: The role of substance P in stress and anxiety responses. Amino Acids 2006;31:251272.

17 Kincy-Cain T, Bost KL: Increased susceptibility of mice to Salmonellainfection following in vivo treatment with the substance P antagonist, spantide II. J Immunol 1996;157:255-264.

-18 Bozic CR, Lu B, Hopken UE,Gerard C, Gerard NP: Neurogenic amplification of immune complex inflammation. Science 1996;273:1722-1725.

19 Marriott I, Bost KL: IL-4 and IFN- $\gamma$ up-regulate substance P receptor expression in murine peritoneal macrophages. J Immunol 2000;165:182-191.

20 Marriott I, Bost KL: Expression of authentic substance P receptors in murine and human dendritic cells. J Neuroimmunol 2001;114:131-141.

21 Holzer P, Schluet W, Maggi CA: Substance P stimulates and inhibits intestinal peristalsis via distinct receptors. J Pharmacol Exp Ther 1995;274:322-328.

22 Rasley A, Bost KL, Olson JK, Miller SD, Marriott I: Expression of functional NK-1 receptors in murine microglia. Glia 2002;373:258-267.

23 Zhang S, Zeng X, Yang H, Hu G, He S: Mast cell tryptase induces microglia activation via protease-activated receptor 2 signaling. Cell Physiol Biochem 2012;29:931-940.

24 Gao HM, Hong JS, Zhang W, Liu B: Distinct role for microglial in rotenone-induced degeneration of dopaminergic neurons. J Neurosci 2002;22:782-790.

-25 Friberg H, Wieloch T, Castilho RF: Mitochondrial oxidative stress after global brain ischemia in rats. Neuroscience Lett 2002;334:111-114.

26 Sullivan PG, Thompson MB, Scheff SW: Cyclosporin A attenuates acute mitochondrial dysfunction following traumatic brain injury. Exp Neurol 1999;160:226-234.

27 Minghetti L: Role of inflammation in neurodegenerative diseases. Curr Opin Neurol 2005;18:315-321.

-28 Streit WJ, Conde JR, Fendrick SE, Flanary BE, Mariani CL: Role of microglia in the central nervous system's immune response. Neurol Res 2005;27:685-691

29 Tweedie D, Sambamurti K, Greig NH: TNF-alpha inhibition as a treatment strategy for neurodegenerative disorders: new drug candidates and targets. Curr Alzheimer Res 2007;4:378-385.

-30 Gruol DL, Nelson TE: Physiological and pathological roles of interleukin-6 in the central nervous system. Mol Neurobiol 1997;15:307-339.

-31 Linker RA, Lühder F, Kallen KJ, Lee DH, Engelhardt B, Rose-John S, Gold R: IL-6 transsignalling modulates the early effector phase of EAE and targets the blood-brain barrier. J Neuroimmunol 2008;205:64-72.

- 32 Quintana A, Müller M, Frausto RF, Ramos R, Getts DR, Sanz E, Hofer MJ, Krauthausen M, King NJ, Hidalgo J, Campbell IL: Site-specific production of IL-6 in the central nervous system retargets and enhances the inflammatory response in experimental autoimmune encephalomyelitis. J Immunol 2009;183:2079-2088. 


\section{Cellular Physiology Cell Physiol Biochem 2014;34:768-780

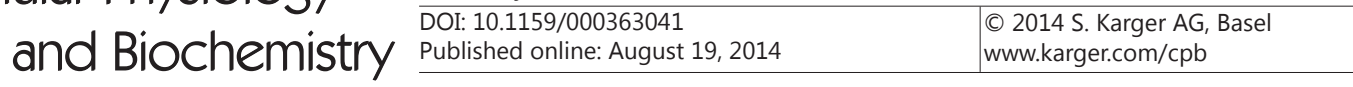 \\ Zhu et al.: Microglia Activation by Histamine and SP}

33 Wei H, Zou H, Sheikh A, Malik M, Dobkin C, Brown T, Li X: IL-6 is increased in the cerebellum of the autistic brain and alters neural cell adhesion, migration and synapse formation. J Neuroinflammation 2011;8:52.

-34 Gadient RA, Otten UH: Interleukin-6 (IL-6)--a molecule with both beneficial and destructive potentials. Prog Neurobiol 1997;52:379-390.

-35 Ikarashi Y and Yuzurihara M: Experimental anxiety induced by histaminergics in mast cell-deficient and congenitally normal mice. Pharmacol Biochem Behav 2002;72:437-441.

-36 Crivellato E, Beltrami CA, Mallardi F, Ribatti D: The mast cell: an active participant or an innocent bystander? Histol Histopathol 2004;19:259-270.

- 37 Ferreira R, Santos T, Gonçalves J, Baltazar G, Ferreira L, Agasse F, Bernardino L: Histamine modulates microglia function. J Neuroinflammation 2012;9:90.

38 Wei J, Wu F, Sun X, Zeng X, Liang JY, Zheng HQ, Yu XB, Zhang KX, Wu ZD: Differences in microglia activation between rats-derived cell and mice-derived cell after stimulating by soluble antigen of IV larva from Angiostrongylus cantonensis in vitro. Parasitol Res 2013;112:207-214.

-39 Meda L, Baron P, Prat E, Scarpini E, Scarlato G, Cassatella MA, Rossi F: Proinflammatory profile of cytokine production by human monocytes and murine microglia stimulated with beta-amyloid[25-35]. J Neuroimmunol 1999;93:45-52.

40 Block ML, Zecca L, Hong JS: Microglia-mediated neurotoxicity: uncovering the molecular mechanisms. Nat Rev Neurosci 2007;8:57-69.

41 Wilkinson BL, Landreth GE: The microglial NADPH oxidase complex as a source of oxidative stress in Alzheimer's disease. J Neuroinflammation 2006;3:30-41.

-42 Akundi RS, Candelario-Jalil E, Hess S, Hull M, Lieb K, Gebicke-Haerter PJ, Fiebich BL: Signal transduction pathways regulating cyclooxygenase-2 in lipopolysaccharide-activated primary rat microglia. Glia 2005;51:199-208.

43 Ciallella JR, Saporito M, Lund S, Leist M, Hasseldam H, McGann N, Smith CS, Bozyczko-Coyne D, Flood DG: CEP-11004, an inhibitor of the SAPK/JNK pathway, reduces TNF-alpha release from lipopolysaccharidetreated cells and mice. Eur J Pharmacol 2005;515:179-187.

44 Lund S, Porzgen P, Mortensen AL, Hasseldam H, Bozyczko-Coyne D, Morath S, Hartung T, Bianchi M, Ghezzi P, Bsibsi M, Dijkstra S, Leist M: Inhibition of microglial inflammation by the MLK inhibitor CEP-1347. J Neurochem 2005;92:1439-1451.

45 Waetzig V, Czeloth K, Hidding U, Mielke K, Kanzow M, Brecht S, Goetz M, Lucius R, Herdegen T, Hanisch UK: c-Jun N-terminal kinases (JNKs) mediate proinflammatory actions of microglia. Glia 2005;50:235-246.

-46 Marriott I, Bost KL: Substance P receptor mediated macrophage responses. Adv Exp Med Biol 2001;493:247254.

47 Lotz M, Vaughan JH, Carson DA: Effect of neuropeptides on production of inflammatory cytokines by human monocytes. Scienc 1988;241:1218-1221.

-48 Laurenzi MA, Persson MA, Dalsgaard CJ, Haegerstrand A: The neuropeptide substance P stimulates production of interleukin 1 in human blood monocytes: activated cells are preferentially influenced by the neuropeptide. Scand J Immunol 1990;31:529-533.

-49 Hartung HP, Wolters K, Toyka KV: Substance P: binding properties and studies on cellular responses in guinea pig macrophages. J Immunol 1986; 36:3856-3863.

-50 Luber-Narod J, Kage R, Leeman SE: Substance P enhances the secretion of tumor necrosis factor-alpha from neuroglial cells stimulated with lipopolysaccharide. J Immunol 1994;152:819-824.

-51 Lai JP, Zhan GX, Campbell DE, Douglas SD, Ho WZ: Detection of substance P and its receptor in human fetal microglia. Neuroscience 2000;101:1137-1144.

-52 Rasley A, Marriott I, Halberstadt CR, Bost KL, Anguita J: Substance P augments Borrelia burgdorferi-induced prostaglandin E2 production by murine microglia. J Immunol 2004;172:5707-5713.

-53 Medina MA, Quesada AR, de Castro I, Sánchez-Jiménez F: Histamine, polyamines and cancer. Biochemical Pharmacology 1999;57:1341-1344.

-54 Saligrama N, Noubade R, Case LK, del Rio R, Teuscher C: Combinatorial roles for histamine H1-H2 and H3-H4 receptors in autoimmune inflammatory disease of the central nervous system. Eur J Immunol 2012;42:15361546. 